\title{
VOCABULARY ACQUISITION AND DEVELOPMENT
}

\author{
Thelma Belmonte
}

\section{RESUMO}

Esse artigo tem como objetivo principal trazer para reflexão alguns aspectos referentes à consciência do aprendizado de uma segunda língua em relação à aquisição e desenvolvimento de vocabulário. Para este fim, esse artigo abordará primeiramente diferentes tendências no aprendizado de línguas focando em teorias linguiísticas, estruturas sintáticas e abordagens humanísticas. Na seqüência, ele considerará as habilidades produtivas e receptivas e algumas barreiras em tal aprendizado. Logo após, o foco passa à influência da leitura no aprendizado de línguas.Finalmente, ele apresenta algumas sugestões para professores e estratégias para construção de vocabulário e também uma conclusão final sobre o assunto.

\begin{abstract}
This article has as its main objective to bring forward into reflection some aspects concerning the awareness of a second language (SL) learning in relation to vocabulary acquisition and development. For this end, this article will first approach different trends on language learning focusing on linguistic theories, syntactic structures, and humanistic approaches. Next, it will consider the receptive and productive skills and some barriers on language learning. Then, the focus turns to the reading influence on language learning. At last, it presents some suggestions for teachers and strategies for vocabulary building and a final conclusion about the matter.
\end{abstract}

There are a number of different reasons for language study and principally for English study. Going back to 1945, with the end of the Second World War, we find an age of scientific, technical and economic activity on an international scale. Technology and commerce were two dominant forces, which generated a demand for an international language. For various reasons, most notably the economic power of the United States in the post-war world, this role fell to English. English became the accepted international language of technology and commerce, it created a new generation of learners who knew specifically why they were learning a language - businessmen/women who wanted to sell their products, mechanics who had to read instruction manuals, doctors who needed to keep up with developments in their fields, and a whole range of students whose course of study included textbooks and journals only available in English. This development was also accelerated by the Oil Crisis of the early 1970s.

From that time this awareness of language learning has promoted interest in linguists and since then theories of language learning and approaches to language teaching have been developed in order to come to conclusions about a methodological approach to the subject. Among them we can remember Skinner's Behaviorist philosophy according to which acquisition of language is the result of conditioning. On the contrary, the Cognitive philosophy of Chomsky maintained that language learning should be seen as the ability to be creative on the basis of acquired rules. More recent investigations have centered on the distinction between 'acquisition' and learning. 
Krashen $(1981,1984)$ characterized learning a language as only 'knowing about' the language, while acquiring a language as the 'knowledge of a language', and, in Krashen's view, acquiring a language is more successful and long lasting than learning it. Like Krashen, Prabhu (1987) believed in the importance of the development of comprehension before production, and Allwright (1977) saw meaning as the focus where language learning can take care of itself.

Humanistic approaches also gained prominence. In such methodologies the experience of the student is what counts and the development of their personality and the encouragement of positive feelings are seen to be as important as their learning of a language. Moscowits (1978) is an example of this student-centered development - the students themselves, their lives, and relationships are the topics to practice grammar or vocabulary. It is also possible to mention studies on self-directed learning (Giblin \& Spalding, 1988), on communicative approach (Brumfit \& Johnson, 1979), on balanced activity approach (Rossner \& Bolitho, 1990), among the various trends.

From all the research cited above, we can conclude that the learning process is the necessary dominant factor in language teaching. It is also curious to reflect that the chief objectives of this research focus on issues of educational pedagogy; the concentration is in linguistic theories, syntactic structures, and analysis of discourse, for example. Vocabulary building has been de-emphasized in language teaching, much to the detriment of the students, who have mostly been left to fend themselves. Nevertheless, this situation has changed. Vocabulary has rapidly changed in status from a 'neglected aspect of language learning' (Meara, 1980) to an area of growing research and publication. There are now theories of L2 vocabulary acquisition, a wide and growing range of teaching techniques available, and a greatly increased awareness on the part of most teachers and learners of the importance of vocabulary development. Saville-Troike (1984: 199) states that 'vocabulary knowledge in English is the most important aspect of oral English proficiency for academic achievement'. According to Carter and McCarthy (1988) the study of vocabulary is at the heart of language teaching and learning. Hubbard (1986) claims that words establish 'talent, aptitude, and human relations'. And also that the understanding of words, the use of words, and the application of words enable a person to develop skills and improve abilities. Morgan and Rinvolucri (1993) also share these ideas stating that words are 'essential, and the lack of them leads to feelings of 'insecurity'. Huckin (1986: 58) reports from his studies that 'vocabulary knowledge is the most important linguistic variable in SL acquisition and performance. The more vocabulary a learner has, the more command of the language he has'. And to present a final concept in this great number of citations, I will conclude with Hammer's (1994: 153) idea about the importance of vocabulary:

If language structures make up the skeleton of language, then it is vocabulary

that provides the vital organs and the flesh. An ability to manipulate grammatical

structure does not have any potential for expressing meanings unless words are used.

We can understand that the need to teach language structure is obvious, since grammatical knowledge allows to generate sentences, but, at the same time, we must 
have something to say, we must have meanings that we wish to express, and we need to have a store of words that we can select from when we wish to express such meanings. Thus, it is possible to assert that vocabulary acquisition have an important role in language learning and how this process has been accomplished is of our particular interest in this study.

Firstly, we have to take into consideration that vocabulary acquisition has to do with receptive skills - reading and listening - and that these skills can positively influence productive skills - writing and speaking (Meara, 1980). Students who read and listen a lot seem to acquire English better than those who do not. One of the main advantages of reading and listening is that it improves the general English level, students receive 'input' and so, they can transform it into 'output'. However, it should be mentioned that being able to understand a text does not necessarily mean that students are able to write or to speak. All over the world there are people who can read English but who are unable to speak it very well. Then, it seems adequate to say that an interactive process between the receptive and the productive skills should be of teachers' concern.

Receptive skill work should involve students in reading or listening where they are able to process the language sufficiently at least to extract meaning. Krashen (1984) puts that one aspect of the receptive skills that concerns SL teachers is that reading or listening in a foreign language creates barriers for the learners - fear of failure or simple frustration - which may make these skills and sub-skills more difficult to use. However, he admits, if teachers can make students feel less anxious, use appropriate teaching techniques and material, then the benefits will be obvious. The students feel that they have succeeded and this way, the barriers to reading and listening are slightly lowered, and, if this process is frequent, students feel more and more confident when they read or listen to something (Willis, 1981). As a result, their productive skills will gradually improve, as well.

Although there are several propositions to second-language (SL) learning through syntactic structure, vocabulary research has indicated that vocabulary acquisition and development are intimately connected to concerns with language learning. It is widely agreed among educators that of the four language skills, viz., reading, listening, writing, and speaking, reading is the one most suitable to the development of vocabulary knowledge (Beck \& McKeown, 1991).

Reading is an exercise dominated by the eyes and the brain. The eyes receive messages and the brain then has to work out the significance of these messages. Unlike a listening text, a reading text moves at the speed of the reader, s/he decides how fast s/he wants or can read it, whereas listeners often have to do their best with a text whose speed is chosen by the speaker. Just and Carpenter (1987) present a number of reasons for vocabulary learning through reading. First, written texts are self-contained, in the sense that they describe their own context more explicitly than verbal texts do. As a result, they are more likely than spoken texts to contain uncommon words and phrases. Second, when students encounter such items, they can refer to the surrounding written context to try to find out their meaning. Third, reading allows students to proceed at their own pace; if they need to re-read a section several times in order to figure out its 
meaning, they can. Also, reading is a communicative activity, not an artificial linguistic exercise; if the passage is interesting, students will become absorbed in it and will try to extract information from it. Finally, reading is convenient and practical; it does not depend on equipment or native-speaker teachers. Reading and listening develop vocabulary in the same way writing and speaking are factors to help retention.

Just and Carpenter (1987) analyze the existing relationship between reading comprehension and vocabulary acquisition. Reading comprehension involves a variety of syntactic, semantic, and referential processes and these same processes can be used to infer the possible features of meaning of an unknown word, the process of contextual analysis. At this point, we might wonder whether these two highly complex mental activities can be carried out simultaneously. Focusing on unknown words in the text ignoring the meaning of the text as a whole, could interfere with the development of efficient reading skills. On the other hand, focusing on the overall meaning of a text while paying only superficial attention to unknown words could inhibit vocabulary building.

Many pedagogical practices seem to presuppose that these two activities are indeed in cognitive conflict. Beck and McKeown (1991) state that the teaching of isolated word lists implies that attention to vocabulary building cannot be combined with attention to reading. The use of pre-reading exercises, where words presumed to be difficult for the learner are singled out and taught before the text as a whole is read, also suggests that vocabulary building and reading cannot be carried out simultaneously. Similarly, having students read for main points is normally done in such a way that almost no vocabulary building takes place.

However, there is evidence that these two activities can be carried out together (Beck \& McKeown, 1991). Reading may be defined as a process of constructing a coherent interpretation of a written text, by adjusting linguistic cues in the text with knowledge structures in the reader's mind. This definition admits the view that meaning does not reside uniquely in the text but is created again by each reader (Spiro, Bertram, \& Brewer, 1980). That is, each reader brings his/ her attitudes, opinions, experience, subject-matter knowledge, and so on, to a text and interprets the text accordingly. Reading is therefore simultaneously a 'bottom-up' (linguistic) and 'top-down' (generic) process. The former is data-driven, proceeding linearly and somehow automatically as it incrementally builds up a representation of the text. The latter is concept-driven, enabling the reader to form tentative holistic representations of the text through guessing while the text is being processed. The former needs the latter to resolve linguistic ambiguities and facilitate parsing; the latter needs the former to check the accuracy of its guesses and to help guide news ones. Thus, reading requires simultaneously attention both to individual lexical items and to context (Davies, 1995).

Another point to be considered is that if reading promotes such knowledge, then it would be simple to learn a second language - the more the learners read, the more they would know. However, this is not always the truth. Typically, ESL learners are poor decoders since their vocabulary knowledge is weak, and their reading is affected by poor vocabulary building strategies. Then, considering the points above mentioned, we can conclude that the most probable procedure to diminish defaults in reading and vocabulary learning, is to base the teaching process on the development of strategies for both reading and vocabulary building. 
According to Davies (1995), there are several strategies in the field of reading; let us analyze some of them:

1. Reading to confirm expectations: this technique places great emphasis on the lead-in stage where students are encouraged to predict the content of the text, giving them an interesting and motivating purpose for reading.

2. Reading to extract specific information: students should read the questions or tasks they are going to answer or perform before reading the text. Then they should scan the text to extract the information, which the questions demand.

3. Reading for communicative tasks: the reading of a text is designed to foster a communicative interaction of some kind. A popular reading technique is the reassembling of a text that has become disordered. There are, of course, many other ways of making reading come alive and of getting students interactively involved in the text.

4. Reading for general understanding: this skill involves absorbing only the main points of the text. The reader is not looking for specific points, but rather for whatever is necessary to get an overall understanding of the text.

5. Reading for detailed comprehension/ information: after reading the text the students answer open-ended questions or detailed questions. Most texts lend themselves to detailed comprehension work. This strategy can offer students a valuable opportunity to study written English in detail and thus learn more about the topic and about hoe language is used.

6. Reading for detailed comprehension - function and discourse: it is important for students to understand the way in which texts are structured and to recognize the functions that are being performed. The discourse structure goes into writing and students must be able to decode if they wish to understand the text fully. Context questions, identifying function, and identifying paragraph structure can be helpful for this purpose.

One aspect of reading (and listening) that concerns many teachers and methodologists is the difference between authentic and non-authentic texts (Wallace, 1992). Texts of the former type have been written for native speakers, while those of the latter have been written especially for language students. Such texts sometimes concentrate on the language they wish to teach and they become artificial. In non-authentic texts the language is extremely unvaried. Consequently, we could foresee that non-authentic material would not necessarily make our students better readers or listeners, especially since they would not be acquiring real language. On the other hand, we also know that students become frustrated if they are presented with language that is simply too difficult for them (as authentic material can be). None of the two extremes is useful for our purposes. What we really need, therefore, are texts of which students can understand the general meaning, whether they are truly authentic or not. The texts must be realistic models of written or spoken English. If teachers can find genuinely authentic material which their students can cope with, that will be advantageous; if not teachers should use material which simulates authentic English and the texts should be roughly-tuned rather than finely-tuned. 
Let us now analyze some of the methodologies of vocabulary teaching since these, together with reading strategies, contribute to vocabulary acquisition and development (Curtis \& Glaser, 1983). One of the problems of vocabulary teaching is how to select what words to teach. While it is possible to select what grammar points students should study, there is no such consensus about which words slot into which future meanings. A general principle of vocabulary selection is that of frequency and coverage. For instance, the word 'book' would be an early vocabulary item since it is frequently used by native speakers and has greater coverage than 'notebook', 'textbook', and so on. But the frequency and coverage of word information is not sufficient to select vocabulary. The decision should also be influenced by considerations such as topic, function, structure, teachability, needs, and wants (Mikulecky \& Jeffries, 1996).

Another point to be emphasized is the need to make students aware of different meanings of words so that they can understand about meaning in context and sense relations. Yet, students need to recognize metaphorical language use and they need to know how words collocate (headache but not throatache). They also need to understand in what stylistic and topical context words, idioms, and expressions occur. Not less important is the fact about word formation - how words can change their shape and their grammatical value, too. Of great importance is the identification of prefixes and suffixes and their meanings. Students should also have a notion of spelling and sound because due to these aspects, the grammatical function of the words may differ (nouns and verbs, for example). It is also important to teach students cognates, partial cognates, false cognates, and make them practice discourse patterns such as parallelism. Exposure to word grammar such as countable/ uncountable nouns, verb complementation, phrasal verbs, adjective and adverb positions are important as well.

Besides all these important references, another profitable aspect to work with is the students' interaction with words. Experiments on vocabulary seem to suggest that students remember best when they have actually done something with the words they are learning (Gairns \& Redman, 1986); for instance, making a noun an adjective, giving opposites, putting words together, etc. We should have students do things with words so that they become acquainted with them. We can also involve students with discovery techniques, where they have to discover for themselves what a word means and how and why it is being used. Discovery techniques can vary from simple matching tasks to more complex understandings of connotation and context. At an intermediate level, for example, we can assume that students already have a considerable store of vocabulary. Instead of teaching them new words we can show them examples of words in action and ask them to use their prior knowledge to work out what words can go with others, when they should be used and what connotations they have (Morgan \& Rinvolucri, 1986). In other words, if we provide the right kind of exposure of words to the students and if we provide opportunities for them to practice these words, then there is a good chance that students will learn and remember some or all of them. As Richard Rossner wrote:

The factors that are crucial, surely, are those least easily controlled, such as the relevance of a word to an individual's immediate wants, needs and interests, the impact on his or her 'affect' on the first few encounters, and the number of 
Not all vocabulary can be learned through interaction and discovery techniques. There are many occasions when some form of presentation and/ or explanation is the best way to bring new words into the classroom. Morgan and Rinvolucri (1986) cite many examples:

1. Realia: the teachers bring objects into the classroom (e.g., postcard, ruler, pen) and says the word, students repeat and construct sentences with the new words.

2. Pictures: board drawings, wall pictures, charts, flashcards, and many other visual representation can be used to explain the meaning of vocabulary items.

3. Mime, action, and gesture: actions, in particular, are probably better explained by mime; times by gestures; prepositions by actions.

4. Contrast: meaning can be taught by contrastive ideas. The meaning of 'empty' can be contrasted with 'full', 'cold' with 'hot'. We can also present these concepts with pictures or mime.

5. Enumeration: we present words with general meaning and go to words with specific meaning. We can say 'clothes' and explain this by enumerating or listing various items of clothes.

6. Explanation: it is more appropriate with more intermediate students because they have a larger knowledge of the language. Explaining the meaning of a word one must include any facts concerning the use of the word and work with examples illustrating the use of the word.

7. Translation: it can be a good idea to solve a presentation problem, but it may discourage students from interacting with the words.

What must be remembered is that we should not introduce words without making sure that students know how they are pronounced. Pronouncing the words should enable students to use them in speech and this, in turn, might help them retain as well as retrieve the new vocabulary.

Sometimes we should let students work on their own pace. Teachers can train students to guess from context. Clarke and Nation (1980) suggested a strategy which learners can use to ensure that they are making good use of the available context clues. It is expected that as the learners become more proficient in the use of the clues, they will not need to follow the steps of the strategy so rigidly. The strategy presupposes two things: firstly that the learners are able to follow the ideas in the text they are reading this means sufficient command of vocabulary, grammar and reading skills in order to achieve basic comprehension, and secondly that the learners bring some relevant background knowledge to the text. This strategy consist of five steps:

a. Finding the part of speech of the unknown words. 
b. Looking at the immediate context of the unknown word and simplifying this context if necessary.

c. Looking at the wider context of the unknown word. This means looking at the relationships between the clause containing the unknown word and surrounding clauses and structure.

d. Guessing the meaning of the unknown word.

e. Checking that the guess is correct.

The text to be used must be understandable and the frequency of unknown words should not be high, avoiding this way a word-by-word reading. Learning vocabulary through context must be the major way of increasing vocabulary knowledge. However, learners must be encouraged to read substantially and develop the skills of guessing from context.

Trying to discover the meaning of an unknown word from the text is a valuable strategy, but sometimes students cannot understand the necessary meaning of an unknown word, even working with the guessing strategies. Learners need to clarify the meaning before they can continue with the text they are working on. If unknown words impede comprehension after having tried various means to get to their meanings, it is reasonable to encourage students to make use of dictionaries (Harmer, (1991).

Most students consult a bilingual dictionary to find an equivalent in their own language. The problem is that bilingual dictionaries do not usually provide sufficient information for the students and this lack of information could lead to serious errors of translations. Thus, our job is not to try to prevent their use, therefore, but to show them how helpful dictionary practice with a monolingual dictionary can be. In it there are so many more words than students will ever see in class; there is more grammatical information about the words; information about pronunciation, spelling, word formation, metaphorical and idiomatic use. There should also be examples of words in sentences and phrases.

Although students at beginners or elementary levels cannot access this information, as their English starts to improve, we should begin to introduce them to monolingual dictionary practice, so that they can appreciate the information that they will find.

While we want to encourage sensible dictionary use, we do not want students to be checking every word of a reading text in their dictionaries when they should be reading for general understanding. A dictionary can be a powerful tool, not always perfect, but nonetheless a useful one. What is necessary is to train students in how to use the dictionary to best advance.

After exploring some of the learning processes to understand how vocabulary can be acquired and developed, we came to the conclusion that there is obviously no perfect way to work with the matter, but it is clear that reading can really improve vocabulary development to a satisfactory level and teachers have a vital importance in the process. For learning to be effective, attention must be paid to the student's own process of learning. Teachers need to be flexible, use innovative, stimulating exercises and practices for their own pleasure, satisfaction and renewal as much as for their students' benefit. 
Vocabulary teaching has a long history and there is plenty of work still to be done and various approaches from different perspectives to be considered.

\section{References}

Allwright, R. (1977). Language learning through communication practice. ELT Documents, $76 / 3$.

Beck, I. \& McKeown, M. (1991). Conditions of vocabulary acquisition. In R. Barr, M. Kamil, P. Mosenthal, \& P. Pearson. Handbook of reading research. Vol. II. (pp. 789-814). New York: Longman.

Brumfit, C. \& Johnson, K. (Eds.), (1979). Communicative approaches and communicative processes. The communicative approach to second language learning. Oxford: Oxford University Press.

Carter, R., \& McCarthy, M. (Eds.) (1988). Vocabulary and language teaching.

New York: Longman.

Clarke, D., \& Nation, I. S. P. (1988). A strategy for guessing from context. In R. 107).

Carter \& M. McCarthy (Eds.). Vocabulary and language teaching. (pp. 104-

New York: Longman.

Curtis, M. E. \& Glaser, R. (1983). Reading theory and the assessment of reading achievement. Journal of Educational Measurement, 20, 133-147.

Davies, F. (1995) Introducing reading. New York: Penguin

Gairns, R. \& Redman, S. (1986). Working with words. Cambridge: Cambridge University Press.

Giblin, K., \& Spalding, E. (1988). Setting up a course involving self-directed learning. The Bell Education Trust Academic Reports, 14, 83-99.

Harmer, J. (1991). The practice of English language teaching. New York: Longman. 
Hubbard, L. R. (1986). Basic manual for English (chap. 2). New York: Avon Books.

Huckin, T. N. (1986). The use of discourse patterning in foreign-language reading and vocabulary acquisition. D.E.L.T.A., 2 (1), (pp.57-75).

Just, M. A., \& Carter, P. A. (1987). Vocabulary acquisition. The psychology of reading and language comprehension. Massachusetts: Allyn and Bacon.

Krashen, S. (1981). On routines and patterns in language acquisition and performance. Second language acquisition and second language learning. (pp. 113-122). Oxford: Pergamon Press.

(1984). We acquire vocabulary and spelling by reading: additional evidence for the input hypothesis. Modern Language Journal, 73 (4), (pp. 440-464).

Meara, P. M. (1980). Vocabulary acquisition: a neglected aspect of language learning. Language Teaching and Linguistics: abstracts, 13 (pp. 221-246).

Mikulecky, B. S., \& Jeffries, L. (1996). More reading power. New York: AddisonWesley.

Morgan, J., \& Rinvolucri, M. (1986). Vocabulary. Oxford: Oxford University Press. Moscowitz, G. (1978). Caring and sharing in the foreign language classroom. New York: Newsbury House.

Prabhu, N. S. (1987) Second language pedagogy. The Bangalore project. (pp.78-81). Oxford: Oxford University Press.

Rossner, R. (1987). Review of 'Working with words'. ELT Journal, 41/4.

Rossner, R., \& Bolitho, R. (Eds.). Currents of change in English language teaching. Oxford: Oxford University Press.

Saville-Troike, M. (1984). What really matters in second language learning for academic achievement. TESOL Quarterly, 18/2, (pp. 199-200).

Spiro, R. J., Bertram, B. C., \& Brewer, W. F. (Eds.), (1980). Theoretical issues in reading comprehension. New York: Lawrence Erlbaum. 
Wallace, C. (1992). Reading. Oxford: Oxford University Press.

Willis, J. (1981). Teaching English through English. London: Longman.

Endereço para contato e correspondência:

CEFET PR - Unidade de Pato Branco

Via do Conhecimento, Km 1

85503-390 Pato Branco - PR

E-mail: belmonte@qualinet.com.br 